FUEL GAS.$$
\text { BY c. }
$$

The enormous consumption of natural gas in the last decade has greatly advanced the demand for a fuel gas. Aside from its extensive use in factories and blast-furnaces, housewives, after coming to know the ease and cleanliness with which agas fire can be started ideal. Coal gas comes next, containing, as it does, a goodly portion, say 30 per cent, of marsh gas, with twice as much hydrogen. With carbon as a standard, the heat units of marsh gas are 2.53 , pure hydrogen $4 \cdot 25$, coal gas 1.71 , and water gas but 0.59 .

Now, although coal gas is high in heat units, water gas is a far becter conveyor, and is usually mixed

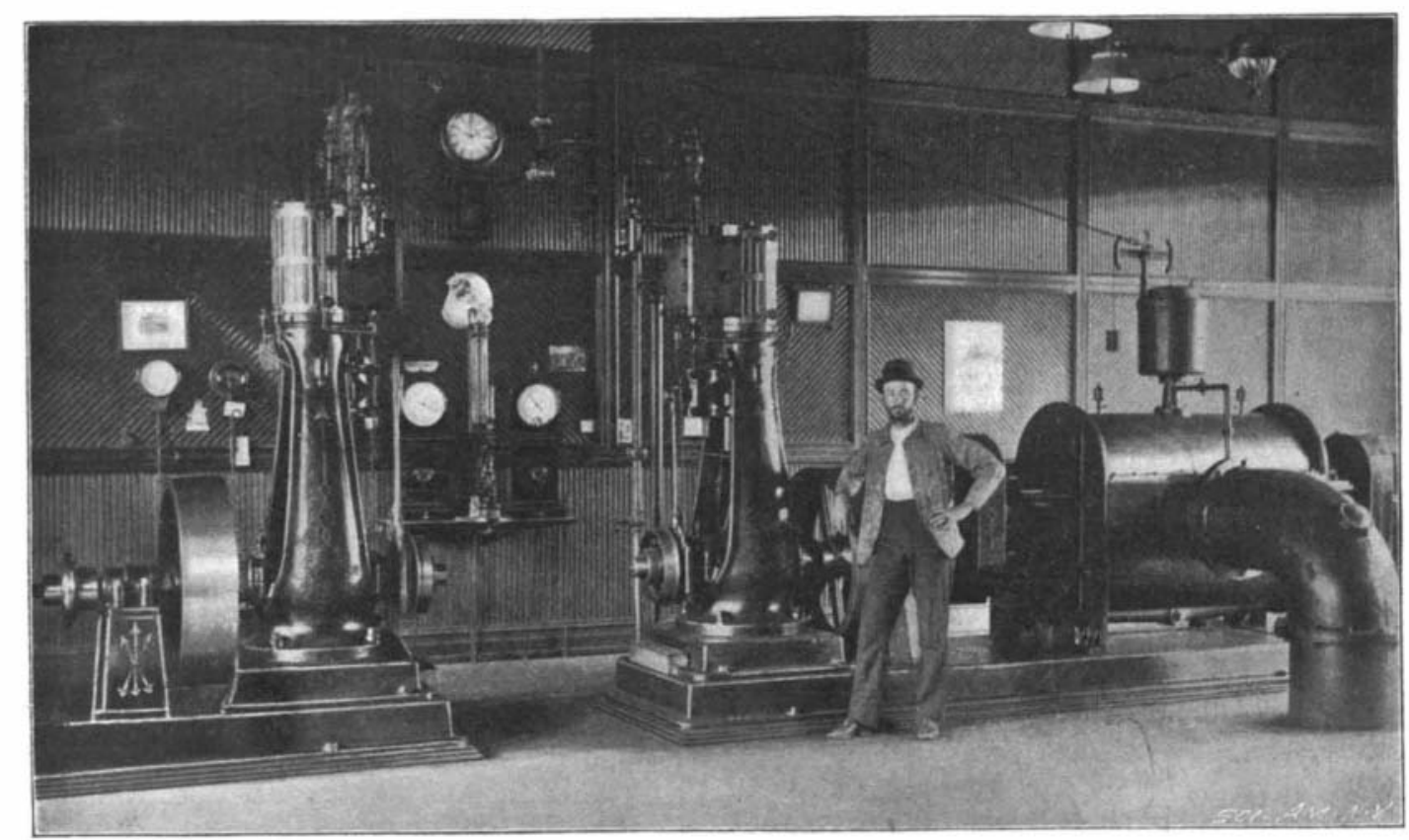

EXHAUSTER ENGINES AND INDICATORS.

and maintained, find a coal stove or kitchen range a rreat hards ip, and very reluctantly accept either, eve when force of circumstances allow them no choice. Similarly the different incandescent mantle burners, most efficient when using a gas which is high in heat units rather than in illuminants, are being received units rather than in illuminants, are being received light is unquestionably the cheapest known, costing scarcely more than $3 / 4$ cent per 100 -candle-power-hour while tip burners require three or four times as muc gas, with a corresponding increase in the amount of deleterious products of combustion. At first, and, in fact, until quite recently, these mantles were too liable to damage from insignificant jars. Knit of cotton in the well-known stocking-top form, afterward dipped in a solution of the oxides of the rare elements didyin a solution of the oxides of the rare elements didyfor use, they were very fragile. This trouble has now, however, in the best made mantles, been practically eliminated.

Another potent factor to be considered in connection with gas making is the gas engine. This motor, re quiring a gas high in heat units, is daily coming int more common use on the score of economy and convenience, and in larger and larger units, although in America they are at present not so much in evidence as abroad. There are to-day in continental Europe more than a score of cities which operate their waterworks by means of gas engines, and at less than hal the expense of well-operated steam-pumps.

It is, therefore, in the manufacture of gas, no longer a question of candle power alone. but the number of calories per cubic foot of gas produced. Of all the gases largely used by man, natural gas, or marsh gas, stands highest in heat units, and for gas engine work is almost

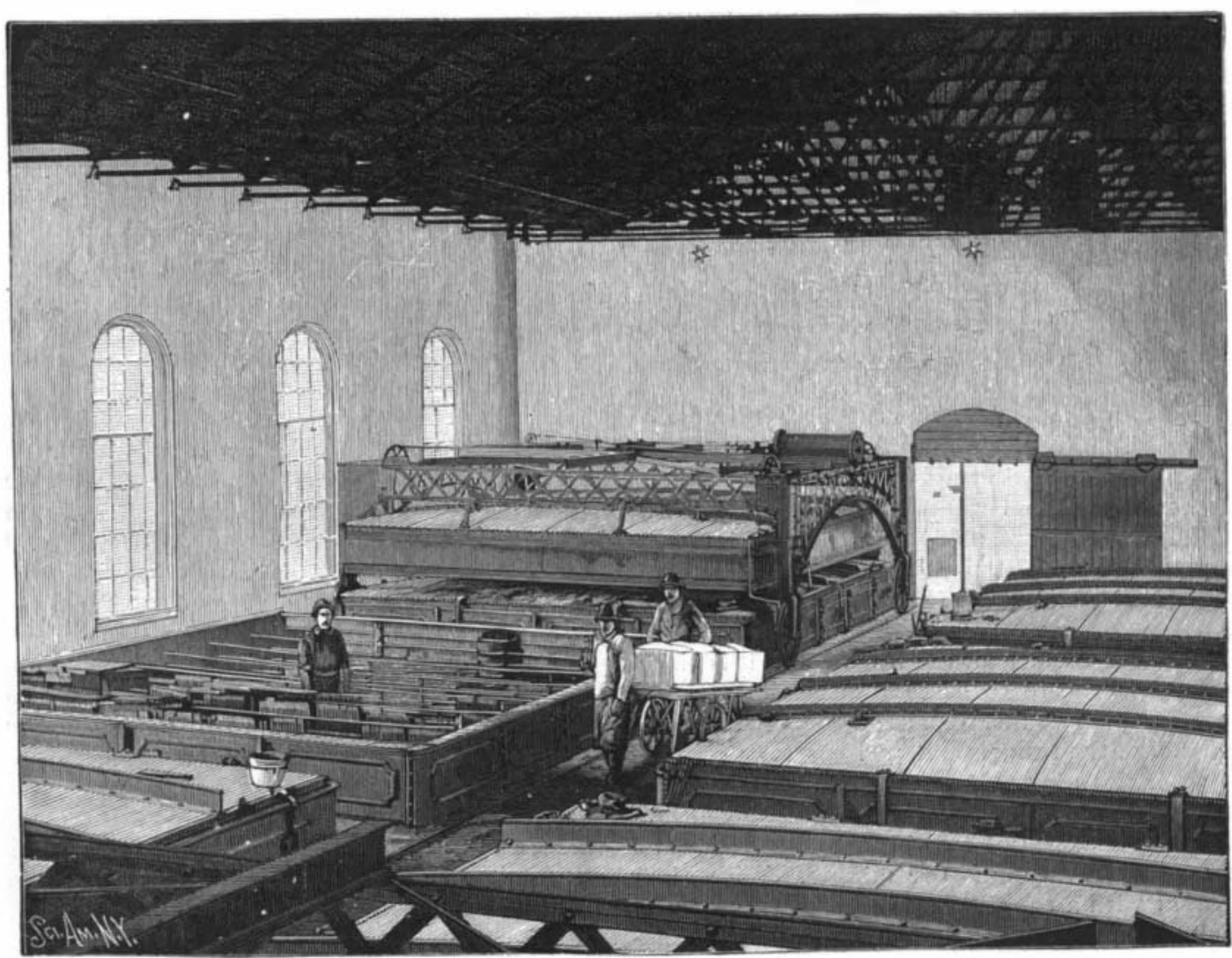

PURIFIERS. nating power, but, unfortunately, cannot be rase a sufficient temperature in a common gas tip to bur well alone. So the two gases have come very comparts of waternbined in about the propoition of two one part of coal gas, with a specific gravity of little more than half as much, say 0.45 with 0.6 as the specific gravity of the mixture. But, notwithstanding coal gas is much the lighter, the vapor tension of the two when combined, although different from the vapor tension of either of them separately, entirely prevents the gases from stratifying in the holder or mains.

Although the mixture of the gases is here given as two to one, the proportion is controlled almost entirely by the exigencies of the case. In some cities a very high candlepower is demanded by the municipal authorities, while in others no attention is paid to the matter, the number of those who want heating gas and of those who want lighting gas being about averaged. Then, too, while coal in some localities is very cheap and the manufacture of coal gas would seem to be most economical, the making of water gas is more nearly automatic, requiring the employment of fewer workmen, thus reducing the margin of loss to the company by strikes and other labor troubles. This leads naturally to a description of what might
be called the new process gas, a process based upon th known fact that water $\left(\mathrm{H}_{2} \mathrm{O}\right)$ in the presence of highly heated carbon (C) is decomposed, forming a new compound known as water gas $(4 \mathrm{H}+\mathrm{CO})$. Though the plant is usually made up of several generators, it suffices to explain the construction and operation of a sin. gle one. The generator is a large sheet iron cylinder. lined inside with thick fire blocks, the top having an opening, say, fifteen inches in diameter closable with opening, say, ffteen inches in diameter, closable with a heavy lid, making a gas-tight joint. From near the top a pipe leads away, through the exhauster, to the
holder, while near the bottom there are two intake pipes, one a blasting pipe from the pressure blower in the engine room, the other from a steam supply. With a fire in the bottom, the generator is filled with coal, or coke, and the blast turned on, which fans the entire charge of coal to incandescence. When the roaring column of blue flame coming from the blow-off has reached a certain fierceness and transparency, a laborer, working a lever, simultaneously closes the lid and shuts off the blast, at the same time opening the steam intake and the gas outlet. The steam coming into contact with the incandescent coal is decomposed, the oxygen taking up carbon and liberating hydrogen, the whole combining to form a gas. Although some substances gasify at as low a temperature as $40^{\circ}$ Fah., others require as high as $150^{\circ}$, the intense heat of the generator, say $2,000^{\circ}$ or more, causes all the substances to gasify at the same moment, and the whole passes off as a stable compound, piped, through the exhauster in the engine room, directly to the holder, where, as it enters, it is mixed with coal gas. Such a degree of exhaustion is maintained as to just relieve the generators of the weight of the holder (shown on indicators in the engine room). This process of charging, blasting, and steaming is repeated every few minutes, with no byproducts.

The simple water-gas process requires few attendants, while the production of coal gas is accomplished at the expenditure of considerable manual labor. Briefly, coal gas is generated in coal or coke charged retorts hented to incandesence but, unlike water gas, retorts heated to incandescence, but, unlike water gas, it cannot be carried direct to the holders, for it must
first be freed of impurities. To begin with, then, the

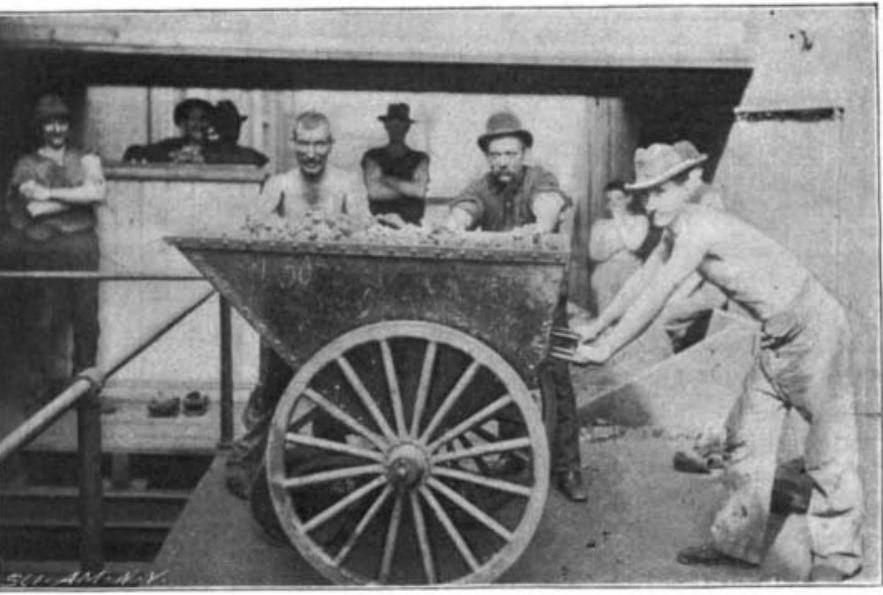

THE CHARGERS.

aborers wheel in coal from the bins in iron carts, from which the stokers charge the retorts. A number of these retorts, fitted with airtight iron doors, are ar ranged side by side and above each other in consider able banks. The retorts are heated and the inclosed coal gasified by burning under them in mammoth Bun sen burners and a system of flues surrounding the $r$ torts, a portion of the purified gas mixed with air, the latter, as a, feature of economy, having been previously heated with the off-heat of the retorts.

These retorts are made from a clay which, after burning, is composed of two parts silica and one part of aluminum, with scarcely a trace of iron or magnesia which, with the great tenacity and elasticity necessary to withstand the strain of drawing and charging, are especially adapted to the high temperatures of present coal-gas practice.

From the retorts the gas is carried to the condensin and purifying houses, where by means of water-seal boxes containing lime and iron oxides, of scrubber and other devices, it is depriverl of tar and gas liquor. The scrubber takes out of the gas a large proportion of the carbon dioxide and all the ammonia, at the same time concentrating the latter into 20-ounce liquor.

The output of purified gas is about 10,000 cubic feet per ton of coal, in well operated ovens. The yield of water gas from a similar ton of sof coal in the generator is 55,000 cubic feet of 10 candle power gas. This can be entiched, however, with benzine or oil ; the addition of 4 gallons of crude oil to 25 pounds of coal or coke producing 1,000 cubic feet of a 20 candle power gas.

However, any kind of gas between the two extremes of high heat and low illumination and low heat and high illumination can be obtained by a proper manipu. lation of the proportious of water gas and coal gas without this enriching process.

So, following the natural law of supply and demand, the nianufacture of gas is slowly but surely undergoing a change adapting it to wider uses and greater consumption. 
New Privileges for the Canadian Nlagara Power Company.

A most important announcement in connection with the Niagara power development was made by Secretary William B. Rankine, of the Canadian Niagara Power Company, on Saturday, July 22. It is to the effect that on July 15 , an amendatory agreement was executed between the commissioners of the Queen Victoria Niagara Falls Free Park, acting in the matter the Canadian Niagara Power Company, under the terms of which the Canadian $\mathrm{Ni}$ agara Power Company is given until July 1,1903 , to develop 10,000 horse power in the Canadian park. 'Tho new franchise is for 110 years. and the rent hase is for 110 years, $\$ 25,000$ to $\$ 15,000$ per annum. Ther are also other ameniments in regard to the location of the plant ind the power house, all the plans fur which have been approved plan for which have been approved. The has yielded it exclusive right to the use of water within the Canadian park, and therefore the commissioners of the park are at liberty to deal with other companies for the development of power outside the territor occupied by the Canadian Niagara Power Company. This agreement was authorized by an act of parliament passed in March last.

The Canadian Niagara Power Company is closely allied to the Niagara Falls Power Company. It is understood that the new chise is far more satisfactory to the chise is far more satisfactory to the power company than the original one was, and it looks as though an the Canadian side was power on deemed as valuable as in 1892 , when the original agreement was made.

Under the provisions of that agreement the Canadian Niagara Power Company was to pay $\$ 25,000$ a year rental for ten years, after which time the rent was to increase $\$ 1,000$ per annum until it reached $\$ 35,000$, and at this it was to remain during the life of the agreement, which might have been extended eighty years, making its total life a century. The company was also to have 10,000 developed horse power by November 1, 1898 , and water connections made for 25,000 horse power. Under the new agreement they are given four years more to develop 10,000 horse power, and the rent is reduced te $\$ 15,000$ a year.

\section{TREE DWELLING IN CALIFORNIA.}

Mill Valley is a suburban hamlet near San Fran eisco and lies at the foot of $\mathrm{Mt}$. Tamalpais, the mos prominent elevation on the bay shore and overlooking an extended prospect. It is the home of many of the wealthiest of San Francisco merchants, who here es cape the fogs and dust of the city and find in genial surroundings that relaxation which is req protracted attention to business. A little stream flows through the precipitous valley, which formerly nourished extensive groves of gigantic redwoods. Many of these great trees have escaped destruction at the woodman's hands and remain to form a most effective and attractive feature of the lovely landscape.

Art has been combined with nature most cheerfully. All the necessities of metropolitan life are afforded the dweller without destroying the primitive charms which have always existed. A friendly rivalry exists among the people as to rivalry exists among the people as to which shall exhibit the greatest novelty
in the architecture of their homes. In no community of its size is there a greate display of eccentricity in this respect manifested. The spurs of the mountains are all adorned by houses of the most peculiar outward appearance, and with interiors which exhibit a rich display of taste ar,d extreme comfort.

play of tllustration shows one howe that has lately been constructed and is re garded as by far the most novel in the valley. It is built around a redwood tree and its floor is 50 feet above the ground. It has four rooms, and communicates with the bluff by a balcony of substantial construction. It is a charming conception and the abode of infinite comfort. There are no destructive beasts of prey or serpents of any kind to escape from in this peaceful valley, and the wild natives that once made this one of their favorite haunts have long ago migrated to the happy hunting

grounds of their ancestors. The suggestion is the fruit of a search for novelty, and in that respect this dwelling surpasses all its neighbors.

\section{Rail Exports.}

The American mail brings some interesting information supplementary to that already cabled over, bearing upon the contract for 180,000 tons of steel rails which has been secured by the Carnegie Company to the order of the Russian government. It is common knowledge that the Russians had been endeavoring for

keep their bly rival

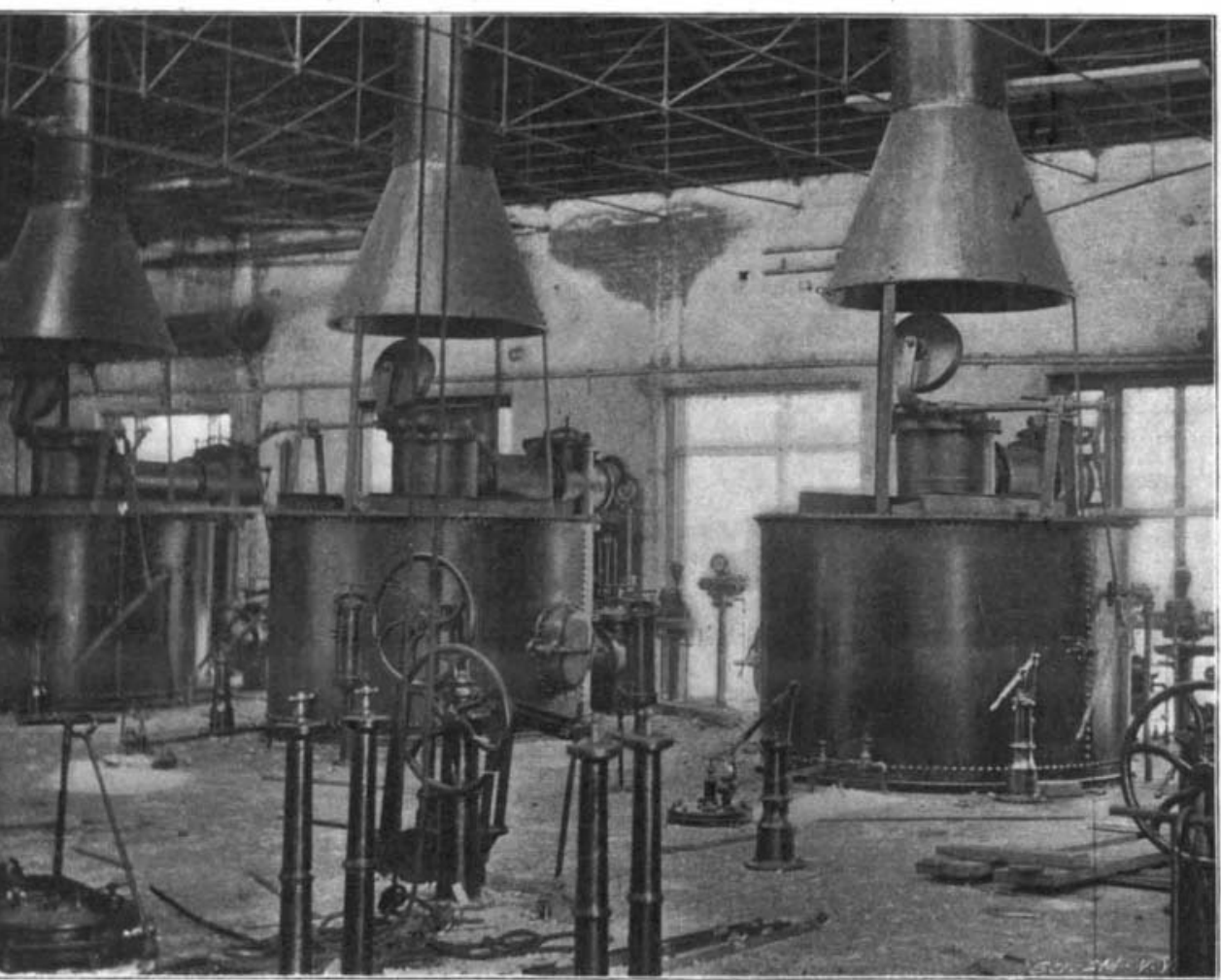

TOPS OF THE GENERATORS

o one in either America or Eurnpe would accept the contract at $\$ 25$ (which was then offered) for delivery within the time required. At however, after wht months of wavering, the order was placed at $\$ 26$ 政 creased cost of $\$ 1,800,000$ to Russia. This huge contract will make itself felt in many directions. "It is expected, for one thing," we are told, " to kfep up the price of pig iron for the next two years. The Carnegie ors confidently hope that it will will be oby during that time that it ness, which will then fall to them." 'I'here is an element of humor in this theory of how Russia was made to "pay through the nose" for its endeavor to be smart, but probably Russia itself will not see the funny side of the business in view of the extra cost. The triumph to America is very considerable, notwithstand. ing the evidence that is afforded of a disinclination on the part of English manufacturers to worry over the securing of the order ; and it draws attention incidentally to the fact that our own foreign trade in rails is not progressing, as a result in a large measure, no doubt. of the advance of our very energetic rivals in the United States. Whatever may be the case with some other branches of enginering some duction thes of engineening production, the seeus no reason for doubt that in more than one market which might be named, we are suffering by the advance of the Americans. This much in relation to Japan, for example, was shown in the recently published report of our consul at Yokohama. Probably the differential rates of the conference steamers have something to do with the greater cheapness several months to place this huge order, and that to of the American article, but whatever the full ex-
secure the best possible terms they had been trying to planation, the fact is there to be faced. Our own play off the English and German makers against the American, and vice versa. At the end of last year the agent was sent to the United States, when rails were sellin at $\$ 16$ per ton, but he failed to close the deal. His government hoped to do better by waiting, and for an excuse there was some objection to certain details in the manufacturing process. He was sent back to Eng the manufacturing process. He was sent back to England, and found on arrival that prices in this country
had risen 5 shillings above the American. Rather had risen 5 shillings above the American. Rather
than pay the equivalent of $\$ 17$ per ton, the Russian government agreed to waive its former objection, and, according to the advices, the agent cabled over to Ame rica renewing the bid, only to find, however, that quotations were by this time $\$ 20$ per ton. So he was sent off to Germany in the hope of getting a better bargain There he found more trouble in the shape of a further advance to $\$ 23$ a ton, with no assurance of early de livery. Then the cable was resorted to again; but by that time the st.eel mills of the world were so busy that

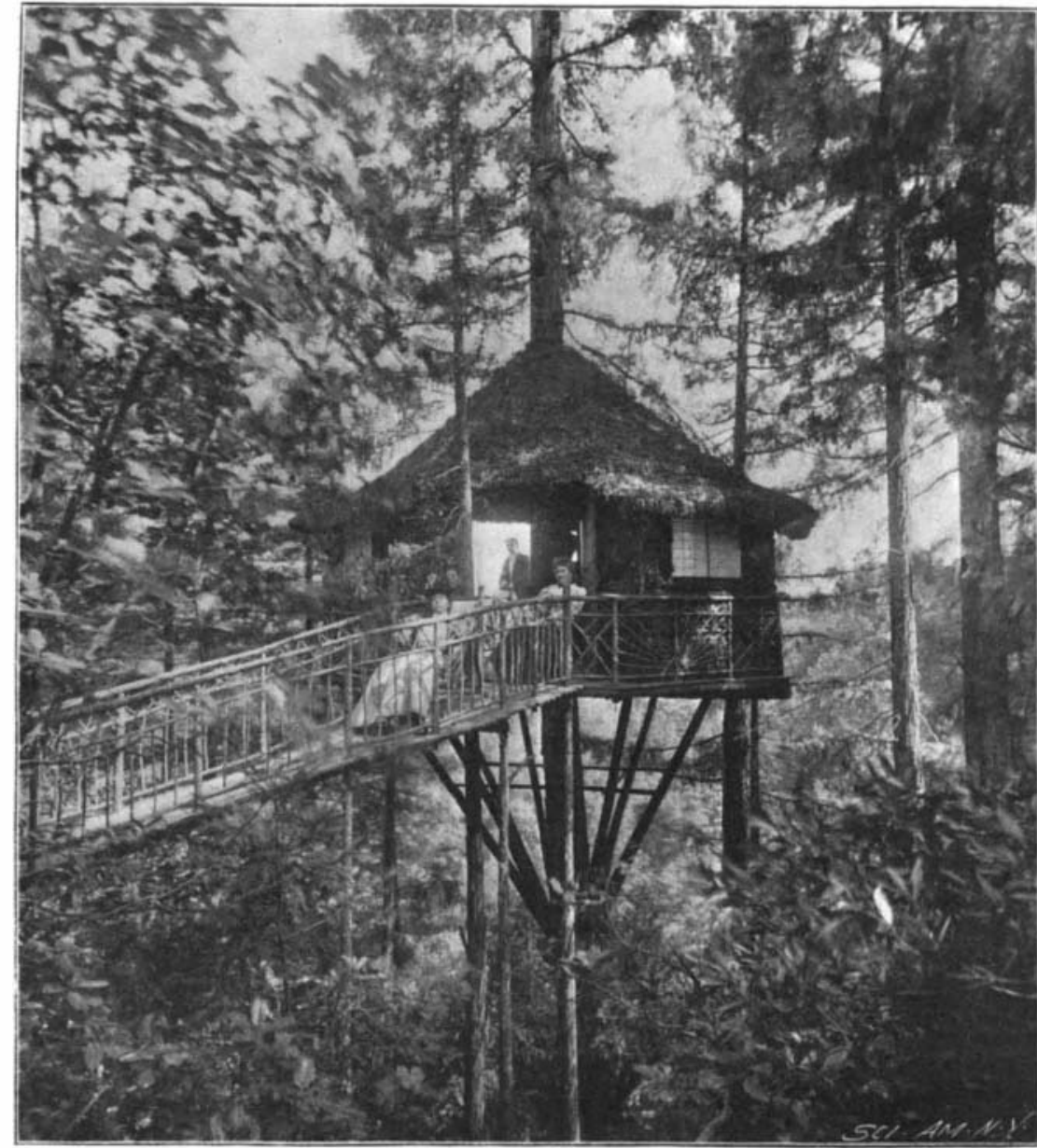

A NOVEL TREE HOUSE IN. CALIFORNIA. trade returns afford conclusive evidence that we are not doing extraordinary things in foreign markets in this respect. For last year our exports of " railroad for $1896,558,375$ tons for 1893 , and $1,035,431$ tons for 1890. It is true that the 1898 total is in excess of any of the four years 1892-95 inclusive, but we do not base our rate of progress altogether on comparisons with a lean series of years any more than on comparisons with a fat series. The fact is that in the last two years we have gone back considerably, and the decline in the takings of Japan, Mexico, Indian, and other markets is referable to American progress. - London Engineering.

Ship Yards and Docks in Japan.

We have received a most interesting letter from $\mathrm{Mr}$. P. J. McCormick, engineer at Yokohaua, Japan, which gives us considerable information regardiug the progress of important works in Japan. Baron Iwasaki, in Tokio, is the owner of the principal engineering and shipbuilding works in Japan, which are situated at Nagasaki. The two dry docks are cut out of soft ruck, and in addition there is a large shipbuilding yard alongside. Last year this concern turned out several large ships, one being a 6,000-ton twinscrew steamer. The engines and boilers will built at the works, where they have powerful cranes. At Kobe a dry dock is being built in sand at enormous expense. At Yokohama there is also a dock which was cut out of soft rock about a year ago, and now another dock has just been finished alongside. A large engine and boiler shop are annexed, and all are owned by the same shipbuilding concern. There are a number of other large docks scattered around Japan, and all are owned by Japanese. 'The government has a number of docks, but no particulars as to their size are obtainable but a short time ago a large English manof-war was successfully docked at one of the government docks. The method of construction of most of them is interest ing. They are nearly all cut out of soft rock, which can be cut with a pick the same as a piece of chalk.

THE Health Board of New York eity states that in the last quarter there were 16,713 , deaths, and that of this
number four had reached the age of oue hundred years or over. 